Family Medicine and Community Health

\title{
Getting started in research, redefined: five questions for clinically focused physicians in family medicine
}

\author{
William Ventres, Leanne Whiteside-Mansell
}

To cite: Ventres W, WhitesideMansell L. Getting started in research, redefined: five questions for clinically focused physicians in family medicine. Fam Med Com Health 2019;7:e000017. doi:10.1136/ fmch-2018-000017

Received 12 September 2018 Revised 26 December 2018 Accepted 24 January 2019
Check for updates

(C) Author(s) (or their employer(s)) 2019. Re-use permitted under CC BY-NC. No commercial re-use. See rights and permissions. Published by BMJ.

Family and Preventive Medicine, University of Arkansas for Medical Sciences College of Medicine, Little Rock, Arkansas, USA

Correspondence to Dr William Ventres; wventres@uams.edu

\begin{abstract}
Research is crucial to the development of family medicine around the world. However, family physicians in practice often hesitate to enter into investigative endeavours. Common reasons for such hesitation include limited exposure to the process of conducting research and the belief that research is best conducted by academic scholars. Our intent here is to encourage clinically focused family physicians' involvement in research activities by explaining how they can cultivate inquisitiveness so as to develop questions for exploration. We present an approach to research that focuses on five steps emergent from the day-to-day, habitual practice of family medicine, wherever in the world it is practised. We illustrate this approach by describing a successful practice-based research study. We conclude by inviting all family physicians to consider integrating research into their practice lives so as to expand their professional horizons and help educate the next generation of global family physicians.
\end{abstract}

Research is important to the discipline of family medicine. ${ }^{12}$ The systematic investigation of pertinent practice-based and community-based issues has helped the discipline grow as an academic endeavour around the world. ${ }^{3}$ It has enabled an entire cohort of academic scholars, clinicians and non-clinicians alike, to come of age in a competitive research environment. ${ }^{4}$ It has introduced new knowledge into the realm of practising family physicians, information critical to the work they do with their patients across the bio-psycho-social-existential spectrum of care. ${ }^{5}$

Nonetheless, most research in family medicine continues to be conducted by professional scholars with institutional support. ${ }^{6}$ Even with the advent of practice-based research networks and community-based participatory research, ${ }^{78}$ the focus of research in family medicine seems predominantly focused on 'big ticket' questions. These kinds of questions can only be addressed through resource-dependent, systems-oriented, methodologically complex investigations consuming of much time, energy and money. ${ }^{9}$
Several have tried to expand the scope of investigative exploration in family medicine beyond traditional boundaries, ${ }^{10} 11$ and requirements for family medicine residents to participate in scholarly activity may serve as a means of encouraging research by more future family physicians, whether or not they intend to pursue academic careers. ${ }^{12}$ At a minimum these efforts have introduced to residents and practising physicians the means to address issues of quality control, assess the medical literature and maintain board certification. Some will, as well, conduct research studies.

This special issue is focused on making effective research methodologies accessible to those working in venues other than major academic settings. In this article, we target family physicians who are first and foremost clinicians and may only occasionally engage in research activities. We mean to encourage their universal involvement in research endeavours, and illustrate how they can both cultivate an inquisitive mindset and develop questions for exploration using the methodologies presented. Accordingly, we redefine family medicine research for use by such occasional investigators, present a rationale for its importance and propose an approach by which all family physicians can easily integrate a structured curiosity into their practice lives.

\section{RESEARCH FOR CLINICALLY FOCUSED FAMILY PHYSICIANS \\ Research redefined}

We define practice-based research for clinically focused family physicians as the process by which they ask and answer questions relating to the process, context and outcome of their work with patients and families, as well as those pertaining to the organisational milieus in which they practise. It is thus part and parcel of being a curious clinician in day-to-day practice. For occasional investigators, research helps nurture a wide-eyed openness to seeing things from new perspectives. 
It enables family physicians to create, out of their daily office environments, laboratory for creative exploration that can serve multiple goals.

\section{Goals redefined}

Just as the interests of clinically focused physician investigators are likely different from those of their colleagues in academic settings, so too are their goals. Several goals are particularly suited to their needs as occasional investigators. These include the following:

1. Developing habits of ongoing reflection in practice, exploring both failures and successes, and analysing why things go wrong as well as why they go right - these are key elements of relational continuity in family medicine and quality assurance, and often play equal parts in patients' and practitioners' lives over time.

2. Improving the quality of practice-based evidence in order to enhance the ongoing work of community-based family physicians.

3. Nurturing personal areas of interest in family medicine, growing skills and knowledge that help one become a mini-expert who acts as a consultant for other physicians in collaborative group practice environments, as is common in the several parts of the world.

4. Sustaining interest in the practice of medicine, especially during a time when many family physicians feel burdened by the bureaucratic aspects of our work, including charting, coding and attending to multitudinous (and often conflicting) practice standards.

5. Building relational links with others, whether with laypeople in the community or colleagues in academic institutions.

\section{A question-oriented approach}

Typical research generally follows a scientific process of posing questions, collecting and analysing data, and reporting results. Such research characteristically emphasises specific methodologies (appropriately matched to the questions posed), systems-level outcomes and processes, and practice-based network behaviours. It focuses on generalisability and group outcomes as final outcomes. However, attending to this process and addressing these concerns may feel overly daunting to individual family physicians in clinical practice.

Due to their high volume of patient care duties, their daily concentration on presenting concerns and their embeddedness in community settings, these same clinically focused family physicians are well suited to generating insight and innovative solutions to important clinical concerns emerging from practice. Hence, we suggest the adaptation of an alternative approach for family medicine investigators who are focused on issues of clinical immediacy.

This alternative approach focuses on five inquisitive steps that come up in the day-to-day, habitual practice of family medicine (see figure 1.) They are not complicated, and one needs no sophisticated training in research methodologies to employ them. Although they do not address the entire research process, they are designed to act as a 'jump start' for those who do not regularly conduct research studies.

These five action steps, and the questions that support them, include the following:

1. Observe: What is going on? This step is one of employing an awareness born of being a participant observer. A participant observer is someone who is simultaneously involved in the process of being a family physician and noticing what is occurring in the practice environment, using critical reflection as a key tool in the process.

2. Ask: Is there a problem? (Or, conversely, are there resiliencies?) This step relies on inquisitiveness. Inquisitiveness is the human quality of being intellectually and emotionally curious as to why events occur, and can be fol-

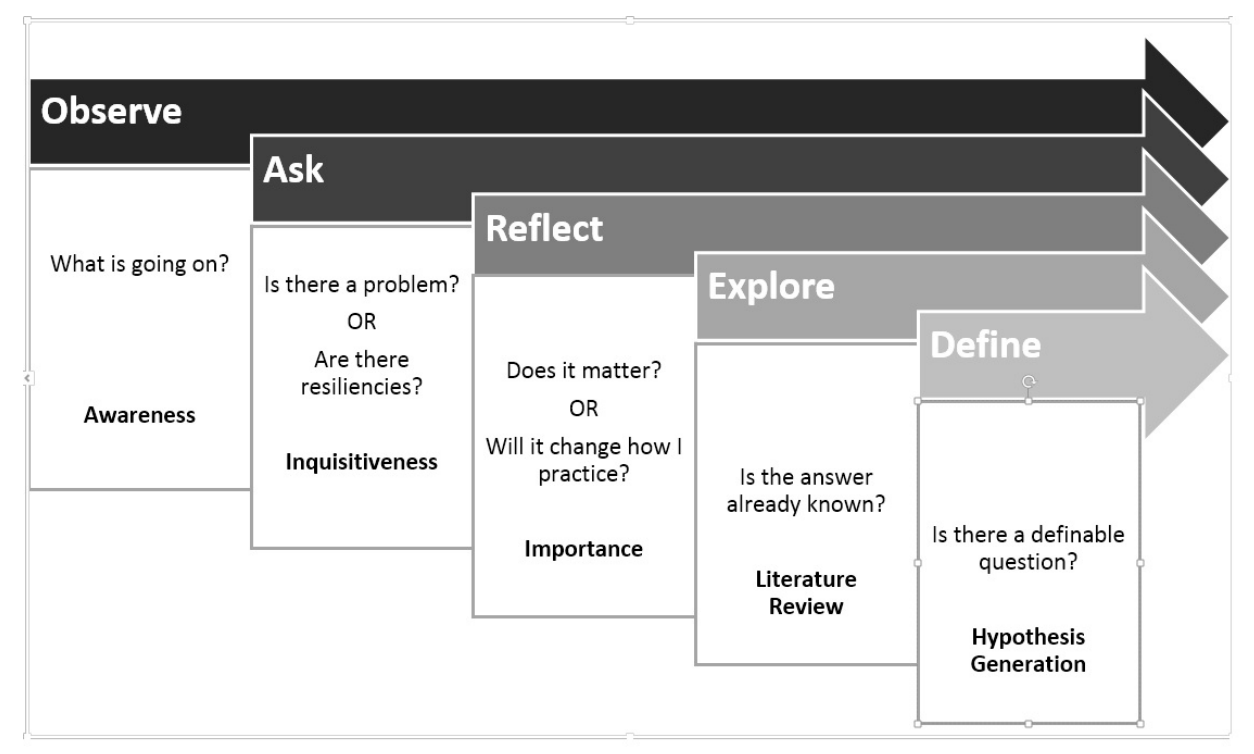

Figure 1 Five steps: a question-oriented process for getting started as a clinically focused family medicine investigator. 
lowed up by refining and honing concerns into practical enquiries.

3. Reflect: Does it matter? Will it change my practice? Asking these questions will help incidental investigators assess the importance of their research endeavours, especially given their intrinsic interests, the time constraints present in day-to-day work and their assessment of potential benefits.

4. Explore: Is the answer already known? This step is a review of the extant literature, examining whether other people have already explored the hypothesis, to what extent and to what conclusion; assessing whether research will continue to fill in gaps in practical knowledge is also part of this step.

5. Define: Is there a definable question? (Or, are there multiple possible questions?) Hypothesis generation is the final 'getting started' step, conjecturing as to the question, why?

\section{The next steps}

There are several additional steps critical to completing research studies in family medicine. These have been covered in detail elsewhere, and generally are more technical in nature. For the incidental investigator, these activities will likely occur in consultation with others. They include the following:

1. Methods: How do I want to explore the problem? While biomedical training often prioritises quantitative research, ${ }^{13}$ qualitative investigations may be more germane to the interests of clinically focused investigators. ${ }^{14}$ These include methods such as intensive case-oriented analyses, narrative studies and observational ethnographies (all of which differ from quantitative ones). ${ }^{15}$

2. Resources: What data collection, management and analysis tools are available to me, and how will I make use of them? In this step investigators assess existing and projected interests, appropriate skillsets, time, and money.

3. Ethics review: How do I get my study approved? Investigative review boards are now commonplace in many countries, and having a working knowledge of their process and function is important. ${ }^{16}$

4. Reporting results: How might I present the results? This step covers the 'where's' and 'how's' of presenting outcomes, evaluation of such concerns as whether to deliver them orally or through written word, in what venues, and how to maximise their intended effects. ${ }^{17}$

5. Writing and rewriting: I want to publish-what other steps are involved along the way? Understanding the peer review process is critical to forestalling concerns about the likely necessity of rewriting and other issues related to the challenges of publishing. ${ }^{18} 19$

\section{CASE STUDY: MAKING SENSE OF THE ELECTRONIC MEDICAL RECORD}

The accompanying research case study briefly illustrates the course of the five-step, question-oriented approach, as noted above. In it, the first author (WV) discusses his experiences in investigating how the electronic health record (EHR) and examination room computers (ERCs) affected communication between family physicians and their patients.

In 1996, back when I was in full-time practice, I was introduced to EHRs. With a lot of fanfare and scant preparation, my partners and I were greeted one day with the presence of computers in our examination rooms. We were told that these ERCs were the future of family medicine, that they would revolutionise the care we provided patients-and little else. It was up to us, for the most part, to figure out how to use them.

Several years later, still not at all confident that I had successfully incorporated either ERCs or the EHR into my care with patients, I asked the question: How do we use these things, and how can we use them effectively to enhance patient care? I knew why ERCs and EHRs were there (an institutional decision) and when they had arrived ( 5 years previously), but as I conducted my work with patients in a relatively solitary fashion I had no idea what others were doing to integrate these tools into their daily flow of practice.

I looked up what was known: at that time, relatively little. There was a lot of hype about EHRs, and an almost equal amount of fear. Quantitative studies showed neither a universal acceptance for EHR use nor a complete rejection: respondents generally exhibited both satisfaction and dissatisfaction in equal measures. A few theoretical articles described their potential use, yet there was almost nothing that I, a busy family physician, could put to practical use to cultivate my competency at using the EHR, let alone assuage my continued angst.

"So what?" I then asked. My answer, not surprisingly, was clear: I had to do something, or else my frustrations with my perceived inability to be a proficient user of ERCs and EHRs would grow; with those frustrations I could envision my satisfaction with being a family physician diminishing.

From those starts, my incidental investigation emerged. I borrowed the anthropological method of ethnography to explore my questions, mostly by observing other clinicians using ERCs during office visits and asking them, immediately afterwards, about that use. I also conducted some focus groups. Nothing rocket science. Along the way, I was fortunate both to receive a small grant that supported some investigative help and publish the written results. ${ }^{20} 21$

I cannot say whether this small investigation changed the course of how my fellow family physicians use the EHR today. Thirteen years since publishing the 'how to' advice I had sought to discover. ${ }^{22}$ I still hear the same issues come up in relation to EHRs and ERCs. I can, however, say that my incidental journey of investigation opened up my eyes in many ways, including how to transform questions into answers, through research in family medicine. 


\section{DISCUSSION}

The work of clinicians in practice is commonly different from the work of academic researchers. So, too, are their motivations to conduct research and the way that they are likely to go about it. In this article we have redefined the definition of research for use by clinically focused family medicine physicians, from one of exploring wide norms to examining specific, relevant understandings. We have examined several research goals appropriate to their particular needs. We have also enumerated a five-step, question-oriented approach to getting started as an occasional researcher in family medicine, and illustrated the application of this approach by means of a case study that reviews the organic process of conducting an investigation. We hope others will consider our approach useful as they look to conduct research in their own right.

We are aware that for this to happen, practising family physicians will need to feel motivated to incorporate research, using our definition above or any other alternative, into their work lives. We believe several key encouraging reasons exist for consideration. First, their work on the front lines of community-based patient care gives them unique perspectives within the culture of medicine, perspectives that emerge from creative engagement with their day-to-day activities. Systematically exploring these practice-oriented perspectives may enhance the value these perspectives deserve. Second, research in these settings can open up opportunities to uncover and share 'eureka' moments filled with the excitement of learning. These moments, and the thoughtful process by which they emerged, may well work as worthy buttresses against the spectre of burn-out. Third, such practice-embedded investigations may challenge conventional perceptions about research, about where it is conducted, what is studied and how it is presented. They may open up new ways of appreciating the challenges, and the worth, of primary care practice. Last, this kind of incidental investigative approach may encourage the kind of reflective practice in which family physicians come to see each patient as a chance to grow and learn, well beyond the basic responsibilities of diagnosis and treatment.

These reasons mirror the historical research activities of several community-based family physicians. Their clinical activities were enhanced by, and several important advances in medicine resulted from, their systematic clinical observation of their practice patients and the lives they lived. ${ }^{23-25}$ More than anything else, it is this kind of systematic observation that we are recommending here. We believe those who adopt such an observational intent-based on the questions we suggest above-will inevitably be drawn to exploring deeply important questions that arise out of their daily work. We believe they will find passionate meaning in learning and sharing the insights they uncover in the process. ${ }^{11}$ All we have done here is to provide a plan for these clinicians, these incidental investigators, to get started down this path of research, redefined.

\section{Limitations}

We recognise there are limitations to our plan, a stepwise approach that emerged from our own experiences with practice-based research. There is, for example, little data on how many family physicians in practice are already doing informal research, or whether those conducting such research would concur with the approach above. Knowledge of these data would likely influence our suggestions. As well, our incidental investigator approach focuses on individual attitudes and behaviours. Structural changes-the development of formal mechanisms by which practising physicians could document, disseminate and highlight their daily observations-might also aid in the evolution of research by practising family physicians. Finally, just as 'no one size fits all', no one approach is universally appropriate. We encourage interested readers to build on our ideas as they grow their practices as generative laboratories for exploring the here and now of everyday interactions with patients and their families.

\section{CONCLUSION}

All family physicians can participate in research, as we have defined it. In this article, we have offered five steps by which incidental investigators can get started in research based on habits of awareness, inquisitiveness and systematic exploration. We suggest that conceptualising and implementing research in this way can help family physicians expand their professional horizons, sustain interest in their practice environments and help them inform the next generation of family physicians as to the realities of everyday practice in family medicine.

Acknowledgements The authors thank Randy Longenecker, MD, and the editors of this special issue for contributing helpful comments on earlier drafts of this article.

Contributors WV and LW-M both contributed to all aspects of the production of this article.

Funding The authors have not declared a specific grant for this research from any funding agency in the public, commercial or not-for-profit sectors.

Competing interests None declared.

Patient consent for publication Not required.

Provenance and peer review Not commissioned; internally peer reviewed.

Open access This is an open access article distributed in accordance with the Creative Commons Attribution Non Commercial (CC BY-NC 4.0) license, which permits others to distribute, remix, adapt, build upon this work non-commercially, and license their derivative works on different terms, provided the original work is properly cited, appropriate credit is given, any changes made indicated, and the use is non-commercial. See: http://creativecommons.org/licenses/by-nc/4.0

\section{REFERENCES}

1. Bowman MA, Lucan SC, Rosenthal TC, et al. Family medicine research in the United States. Fam Med 2017;49:289-95.

2. deGruy FV, Ewigman B, DeVoe JE, et al. A plan for useful and timely family medicine and primary care research. Fam Med 2015;47:636-42. 
3. Peek CJ, Glasgow RE, Stange KC, et al. The 5 R's: an emerging BOLD standard for conducting relevant research in a changing world. Ann Fam Med 2014;12:447-55.

4. Dickinson WP, Stange KC, Ebell MH, et al. Involving all family physicians and family medicine faculty members in the use and generation of new knowledge. Fam Med 2000;32:480-90.

5. Lam CLK. The $21^{\text {st }}$ century: the age of family medicine research? Ann Fam Med 2004;2(Suppl 2):s50-4.

6. Voorhees JR, Xierali IM, Bazemore AW, et al. A small percentage of family physicians report time devoted to research. J Am Board Fam Med 2013;26:7-8. Jr.

7. Graham DG, Spano MS, Stewart TV, et al. Strategies for planning and launching PBRN research studies: a project of the Academy of family physicians national research network (AAFP NRN). J Am Board Fam Med 2007;20:220-8.

8. Macaulay AC. Promoting participatory research by family physicians. Ann Fam Med 2007;5:557-60.

9. Delaney B, Moxham J, Lechler R. Academic health sciences centres: an opportunity to improve services, teaching, and research. Br J Gen Pract 2010;60:719-20.

10. Hueston WJ, Mainous AG. Family medicine research in the community setting: what can we learn from successful researchers? J Fam Pract 1996;43:171-6.

11. Phillips WR. Pursuing personal passion: Learner-Centered research mentoring. Fam Med 2018;50:41-6.

12. Accreditation Council for Graduate Medical Education. ACGME program requirements for graduate medical education in family medicine, 2018. Available: https://www.acgme.org/Portals/0/ PFAssets/ProgramRequirements/120FamilyMedicine2018.pdf [Accessed $31 \mathrm{Jul}$ 2018].
13. Brian Haynes R. Forming research questions. J Clin Epidemiol 2006;59:881-6.

14. Ventres WB, Frankel RM. Ethnography: a stepwise approach for primary care researchers. Fam Med 1996;28:52-6.

15. Crabtree BF, Miller WL. Doing qualitative research. $2^{\text {nd }}$ ed. Thousand Oaks, CA: Sage Publications, 1999.

16. Wolf LE, Walden JF, Lo B. Human subjects issues and IRB review in practice-based research. Ann Fam Med 2005;3(suppl_1):S30-S37.

17. Fah TS, Aziz AFA. How to present research data? Malays Fam Physician 2006;1:82-5

18. Estrada C, Kalet A, Smith W, et al. How to be an outstanding reviewer for the Journal of general internal medicine ... and other journals. J Gen Intern Med 2006;21:281-4.

19. Harvey HB, Weinstein DF. Predatory publishing: an emerging threat to the medical literature. Acad Med 2017:92:150-1.

20. Ventres W, Kooienga S, Marlin R, et al. Clinician style and examination room computers: a video ethnography. Fam Med 2005;37:276-81.

21. Ventres W, Kooienga S, Vuckovic N, et al. Physicians, patients, and the electronic health record: an ethnographic analysis. Ann Fam Med 2006;4:124-31.

22. Ventres W, Kooienga S, Marlin R. EHRs in the exam room: tips on patient-centered care. Fam Pract Manag 2006;13:45-7.

23. Huygen FJA. Family medicine: the medical life history of Dutch families. New York, NY: Brunner Mazel, 1982.

24. Hames CG. Natural history of essential hypertension in Evans County, Georgia. Postgrad Med 1974:56:119-26.

25. Hart JT. The health of coal mining communities. J R Coll Gen Pract $1971 ; 21: 517-28$. 